\title{
Nanogold for In Vitro Inhibition of Salmonella Strains
}

\author{
Mercy Adusei Boatemaa ${ }^{D},{ }^{1}$ Ramachandra Ragunathan, ${ }^{2}$ and Jishnu Naskar ${ }^{3}{ }^{3}$ \\ ${ }^{1}$ All Nations University College, Koforidua, Ghana \\ ${ }^{2}$ Centre for Bioscience and Nanoscience Research (CBNR, Affiliated to Bharathiar University), Coimbatore, India \\ ${ }^{3}$ Jacob Institute of Biotechnology and Bioengineering, Sam Higginbottom University of Agriculture, Technology, and Sciences, \\ Allahabad, U.P, India
}

Correspondence should be addressed to Mercy Adusei Boatemaa; abmercy14@gmail.com

Received 29 August 2018; Accepted 28 February 2019; Published 19 June 2019

Academic Editor: Xuping Sun

Copyright $\odot 2019$ Mercy Adusei Boatemaa et al. This is an open access article distributed under the Creative Commons Attribution License, which permits unrestricted use, distribution, and reproduction in any medium, provided the original work is properly cited.

\begin{abstract}
The pathogenic strains of Salmonella typhi, paratyphi, and typhimurium are the major cause of typhoid and food poisoning in children and adults in developing countries. According to WHO estimation, 22 million cases of typhoid fever and 200,000 related deaths occur worldwide each year with an additional 6 million cases of paratyphoid fever estimated to occur annually with the highest incidence in children, resulting in a high death rate. The high use of antibiotics has also given rise to drug-resistant strains. Hence, it was of importance to assess the inhibition and quick detection of pathogenic strains of Salmonella. This study aims to investigate the chemically synthesized gold nanoparticles (GNPs) for its antibacterial activity against clinical isolates of $S$. typhi and S. paratyphi including food sample isolates. The GNPs were characterized using visible color change, UV-Vis spectrophotometry, FTIR, XRD, DLS, FESEM, TEM, and zeta potential. The plasmon peak at $525 \mathrm{~nm}$ and $535 \mathrm{~nm}$ confirmed the synthesis of gold nanoparticles. The size of the chemically synthesized gold nanoparticles (GNPs) were in the range of 40-60 nm, while FESEM and TEM images revealed that the GNPs were spherical in shape. For antimicrobial activities, five of the Salmonella strains were isolated from fish and egg samples, while the other seven were S. typhi and S. paratyphi from clinical samples. The inhibition factor for GNPs showed higher inhibition against $S$. paratyphi, while the inhibition factor for S. typhi were found to be higher than Ciprofloxacin-30. This is the first study of the antibacterial efficacy of GNPs against pathogenic strains of Salmonella. The obtained results suggest that nanobioconjugated gold may be of interest in the detection of typhoid and high potential use in areas in biomedicine as an alternative to antibiotics.
\end{abstract}

\section{Introduction}

The Salmonella spp. are enteric human pathogenic bacteria hazardous to the public health. Salmonella typhi, paratyphi, and typhimurium are the major causes of typhoid and food poisoning, respectively, in children and adults in developing countries. It is therefore relevant to explore the use of new antimicrobial agents for treatment instead of antibiotics as the use of antibiotics has led to the emergence of various drug-resistant strains. Although all noble metals have some potent antimicrobial activity, silver nanoparticles also show significant ability to inhibit the growth of microorganisms and the literature has numerous reports on their therapeutic potentials [1-3]. Furthermore, a comprehensive review article was published highlighting several reports on the antibacterial activity of silver nanoparticles and their therapeutic outcome [2].

Specifically, silver NPs have been reported to have microbial inhibition against Salmonella strains (Salmonella typhi and Salmonella paratyphi) [4]. Also, a green synthesis of silver NPs has been demonstrated to have antibacterial activity against Salmonella typhimurium [5]. It has been further demonstrated that Salmonella growth is greatly inhibited by a synergistic antibacterial activity achieved by combining silver NPs with antibiotics [6]. This study is an attempt to investigate how gold nanoparticles (GNPs) affect these bacteria. Nevertheless, it has been reported that the resistance of various enteric human pathogenic bacteria against many synthetic drugs is being enhanced day by day [7]. According to the earlier published results of the antimicrobial activity of 
GNPs against human bacterial pathogens, it is outlined that there is no significant reaction for the zone of inhibition for E. coli and S. aureus and only $7 \mathrm{~mm}$ and $16 \mathrm{~mm}$ were obtained, respectively $[8,9]$.

Gold nanoparticles (GNPs) have novel properties and applications in nanotechnology and life sciences. It has been used since ancient times to make stained glass, but it was long assumed that the color of the gold suspension was a result of the chemicals used to prepare it. In 1857, Michael Faraday produced the first pure sample of a gold colloid and discovered that its color is due to the size of the gold particles. GNPs have monodispersed nanoparticles with shape- and sizedependent properties, exhibiting the color of ruby/intense red, and a wide range of particle sizes from 5 to $200 \mathrm{~nm}$ is often fabricated and used for diagnostic and therapeutic applications. The properties of GNPs and gold ions that make it unique over other metal nanoparticles are found to be its high surface-to-volume ratio for which a large number of surface gold atoms increase the surface chemical reactivity and enhance the chemisorption of molecules $\left(\mathrm{CO}\right.$ and $\left.\mathrm{H}_{2} \mathrm{O}\right)$ and its applicability for diagnostic, medical, therapeutic, and biological purposes [10-12]. Its properties such as dielectric function, electrical conductivity, and inertness permit its application to sinter inks, selective coatings, data storage, single electron conductivity, and quantum devices [13-15]. Another unique property is the surface plasmon resonance (SPR), which is a physical concept that describes the collective oscillations of conduction band electrons in the electromagnetic field. This property provides a new platform for the detection of many biological, environmental, and biomolecular targets [16-18]. GNP has a strong affinity for sulfur atoms, and this enhances its ability to have its surface modified through various approaches with S-containing compounds for diagnostic, sensing, and environmental applications $[19,20]$. The surface of GNPs can also be modified by many different coating agents having different functionalities to make them useful in biology and medicine $[21,22]$. Nowadays, GNPs have been studied and widely exploited in clinical diagnosis [23], biosensors, immunoassays [24], microorganism control [25], genomics [23], and vaccine development [26].

The various methods for the synthesis of GNPs are grouped under the bottom-up and top-down fabrication techniques [27]. They include chemical [28], sonochemical, electrochemical [29, 30], polymer-mediated [31], UV-induced photochemical [32, 33], ultrasound-assisted $[34,35]$, and laser ablation methods [36], as well as some unconventional (green synthesis or biosynthesis) approaches using microbes and plants. Intracellular and extracellular methods are some of the pathways available for GNP fabrication [37]. The first conventional chemical approach used to synthesized gold (III) derivatives by aqueous citrate was pioneered by Turkevich in 1951 [28]. In this method, the size of the gold nanoparticle obtained are influenced by the ratio of the reducing and stabilizing agents used [38]. Reducing agents such as borohydrate and sodium citrate enabled GNPs to be synthesized in different sizes and shapes (spherical and triangular shapes or in the form of nanorods and nanowires) [39]. However, there are three approaches in the chemical reduction method of synthesis that yield to a size-defined particle. The Turkevich and Frens method is the standard method whereby gold ions are reduced and stabilized by sodium citrate at $100^{\circ} \mathrm{C}$. The UV irradiation at room temperature is another approach. Here, the gold solution with an added amount of citrate in a cuvette is placed in front of a UV lamp with a wavelength of $366 \mathrm{~nm}$ for two hours and the spectra bands were measured using a spectrometer. The third reduction method is by using ascorbic acid as a reducing and stabilizing agent [29]. The author [33] synthesized GNPs in the presence of ascorbic acid and $\mathrm{CTAB}$ to obtain anisotropic GNPs that were applied in semiconductor systems.

Furthermore, the importance of the citrate reduction approach over others denotes that the preparations of GNPs by the chemical method involve two main steps. However, the reduction and the stabilization steps are achieved using sodium citrate in order to avoid aggregation of the particles $[40,41]$ by achieving a nucleation, growth, and coagulation process. The use of trisodium citrate in fabricating GNPs is a low-cost technology that yields high volumes of GNP and reproducible results in terms of shape and size. This makes it the large-scale production approach chosen by industrial manufacturers and used for commercialization purposes [42].

This work is aimed at fabricating gold nanoparticles (GNP) using a low-cost approach, and its various characterizations were done first by visualization of physical color change and then by UV-Vis, FTIR, XRD, FESEM, TEM, DLS, and zeta potential. Salmonella strains obtained from hospitals and some from fish samples were isolated. All the necessary confirmatory tests were performed using TSI and TCBS media. Finally, the antimicrobial activity of GNPs and ionic gold were evaluated by the standard disk diffusion method and the diameters of the zones of inhibitory concentrations were measured. Also, this work focuses on investigating and evaluating the antimicrobial efficacy of pure GNPs on pathogenic strains of Salmonella which has not really been researched as thoroughly as it deserves.

\section{Experimental Section}

2.1. Chemicals and Media Used. Gold (III) chloride trihydrate tetrachloroauric (III) acid $\left(\mathrm{HAuCl}_{4} \cdot 3 \mathrm{H}_{2} \mathrm{O}, \mathrm{M}\right.$. W. 393.83) was purchased from HiMedia Mumbai, India. Sodium citrate $\left(\mathrm{Na}_{3} \mathrm{C}_{6} \mathrm{H}_{5} \mathrm{O}_{7} \cdot 2 \mathrm{H}_{2} \mathrm{O}\right.$, M.W. 294.10) was purchased from Loba Chemie Pvt. Ltd., Mumbai, India. All solutions were prepared in doubled distilled water (demineralized water) obtained from Medilise Chemicals, Kerala, India. A Ciprofloxacin (CIP-30 mcg) disc was procured from HiMedia Mumbai, India. In this study, nutrient agar, TSI, and TCBS media were procured from HiMedia Mumbai, India. All chemicals used were of analytical grade and used without further purification.

2.2. Collection of Salmonella spp. For isolation of Salmonella spp., different clinical samples were collected from three different hospitals in Coimbatore, Tamil Nadu, India. Among the clinical Salmonella strains collected, six were S. typhi 
and one was $S$. paratyphi. Also, different types of fishes and eggs were taken from the Ukkadam fish market, Coimbatore (CBE), Tamil Nadu, India. In this study, all other chemicals and reagents used were procured from HiMedia Mumbai, India. All chemicals used were of analytical grade and used without further purification.

2.3. Isolation of Salmonella from Fish and Egg. The culture methods for the isolation of Salmonellae involve a nonselective preenrichment, followed by selective enrichment, and plating onto selective and differential agars. All samples were aseptically subcultured onto agar slants (HiMedia, Mumbai, India) and incubated at $37^{\circ} \mathrm{C}$ for 24 hours. After culture growth, the slants were used for further studies [43, 44]. The presumptive Salmonella colonies were then subcultured onto the fresh nutrient broth and incubated for $24 \mathrm{~h}$ at $37^{\circ} \mathrm{C}$.

2.4. Isolation and Confirmation of the Salmonella Isolates. The presumptive Salmonella isolates were identified by two confirmatory biochemical tests using the Triple-Sugar-Iron (TSI) agar test and the Thiosulfate-Citrate-Bile SaltsSucrose (TCBS) agar test according to the method in $[45,46]$, and these were used without modification. The presumptive Salmonella colonies were directly stabbed into the TSI and TCBS agar slants, and the inoculated samples were incubated with a loosened cotton plug for $24 \mathrm{~h}$ at $37^{\circ} \mathrm{C}$. The TSI agar was checked for alkalinity and the production of hydrogen sulfide gas, while that of the TCBS was checked for the production of black colonies which confirmed that no trace of Vibrio cholerae was falsely isolated. TSI is used to differentiate specific bacteria from the family Enterobacteriaceae based on their ability to ferment glucose, lactose, and sucrose and also with their ability to reduce sulfur to hydrogen sulfide [43]. The TSI slant was used to detect the lactose fermenters and the saccharose and dextrose fermenters. The medium also helped to determine the ability of the organisms to produce $\mathrm{H}_{2} \mathrm{~S}$. Pinkish slant and yellow butt or black slant and yellow butt were recorded as the positive reaction for Salmonella spp. [43].

2.5. Determination of Antimicrobial Activity from the Isolates. All the isolates that were identified and confirmed as Salmonella spp. were used in antimicrobial susceptibility using the Kirby-Bauer disc diffusion method [47]. The isolated organism was subcultured in nutrient broth for 24 hrs. Nutrient agar plates were prepared; after sterilization, the agar was poured on the plate inside the lamina air flow and allowed to solidify. $70 \mu \mathrm{L}$ of the 24-hour old culture of Salmonella spp. was spread evenly on the agar plate using a sterile cotton swab. After 2 minutes of drying, three different wells $(20 \mathrm{~mm})$ were made on the plate using a cork borer and $25 \mu \mathrm{L}$ and $50 \mu \mathrm{L}$ of GNP and $10 \mu \mathrm{L}$ of gold solution were added on it; a standard Ciprofloxacin disc (CIP-30 mcg) was also placed on it and kept for 24 hours of incubation. The diameters of the inhibitory zones were measured in $\mathrm{mm}$; the values obtained were further analyzed.

2.6. Fabrication of Gold Ions and Colloidal GNPs. The gold ion was synthesized using a standard formula formulated by the CBNR laboratory protocol, Coimbatore, India. A
$2 \mathrm{mM}$ aqueous solution of gold (III) chloride trihydrate (tetrachloroauric (III) acid) was heated in an ultrasonic bath at $100^{\circ} \mathrm{C}$ for five minutes and was reduced by $1 \%$ sodium citrate in dropwise addition. The solution was boiled further for 5-30 minutes at constant heating till it produced a deep cherry red color $[28,48]$. The gold nanoparticle solution was then cooled at room temperature and stored at $4^{\circ} \mathrm{C}$ till use. It was then subjected to various characterizations like UV-Vis spectra, FTIR, FESEM, TEM, XRD, DLS, and zeta potential.

2.7. Characterization Techniques. The microprocessor UV-Vis spectrophotometer (Labtronic, single beam, LT-291, India) analysis was used for the optical analysis of GNPs scanned in the range of $300 \mathrm{~nm}$ to $700 \mathrm{~nm}$ with the UV-Vis spectrophotometer operating at a resolution of $2 \mathrm{~nm}$. The Fourier transform infrared spectrophotometric (FTIR, Shimadzu, IRTracer-100, Japan) analysis was used to determine infrared intensity against the wavelength of light by identifying the functional group involved in the reduction and formation of the synthesized GNPs. A field emission scanning electron microscope (FESEM, GeminiSEM 500, Carl Zeiss, Germany) and TEM analysis were used for the morphological identification of the size and structure of the synthesized GNPs. X-ray diffraction (XRD, PANalytical X'Pert Pro, Diffractometer, Almelo, Netherlands) analysis was used to confirm the structure. It was scanned in the range of $2 \theta\left(10^{\circ}-80^{\circ}\right)$. Dynamic light scattering (DLS, Nano ZS90, Malvern Instruments Ltd., UK) analysis was used to analyze the particle size and zeta potential to help study the physical property as well as the stability and quality of the synthesized GNPs.

\section{Results and Discussion}

3.1. Isolation of Salmonella spp. Salmonella was detected in 12 of the total (30) collected samples under study. Seven were from clinical samples and five were isolated from fish and egg food samples. The Salmonella strains were cultured in nutrient media and were ascertained by turbidity and growth of circular, smooth, opaque, and translucent colonies in nutrient agar plates $[33,34]$.

3.2. Confirmatory Test for Salmonella Isolates Using TripleSugar-Iron (TSI) and Thiosulfate-Citrate-Bile Salts-Sucrose (TCBS). The Salmonella strains were cultured in nutrient media and were ascertained by turbidity and growth of circular, smooth, opaque, and translucent colonies in nutrient agar plates as reported by the authors $[43,49]$. In the TSI slants shown in Figure 1, the organism produced black colonies at the center due to the production of hydrogen sulfide gas. Likewise, in the Thiosulfate-Citrate-Bile Salts-Sucrose (TCBS) slants in Figure 2, the organism produced black colonies confirming the absence of Vibrio cholera in the isolates as reported earlier in the literature [50].

3.3. Color Visualization of the Chemically Synthesized GNPs. The gold nanoparticle was fabricated successfully as observed by a change in color from yellow to purple. The obtained results are shown in Figure 3. 

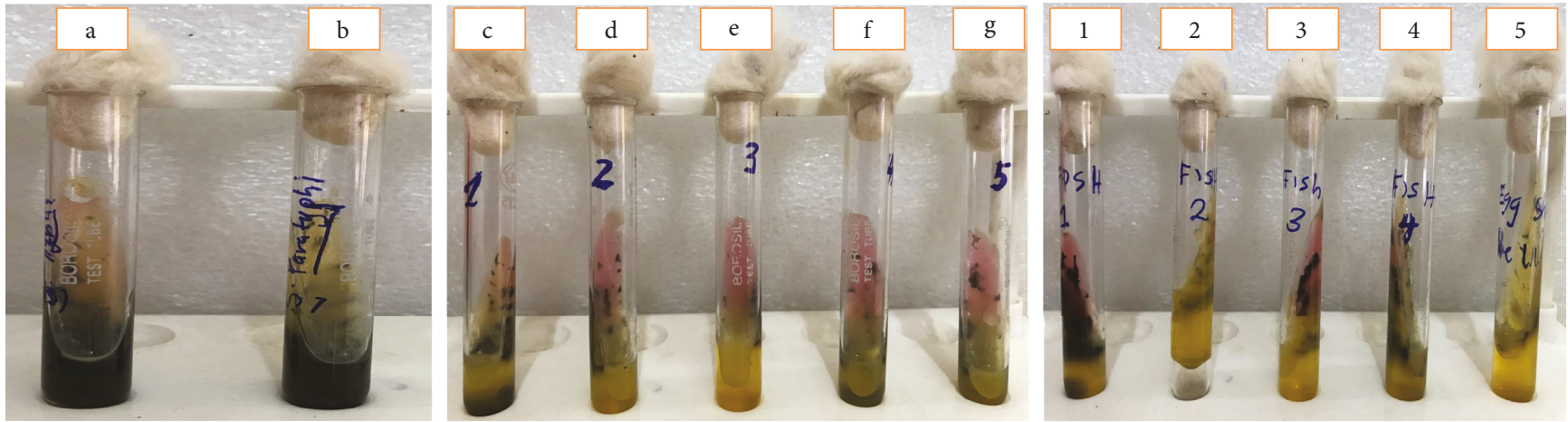

FIGURE 1: Triple-Sugar-Iron (TSI) results after 24 hours of incubation. a-g: clinical isolates; 1-4: fish isolates; 5: egg isolate.

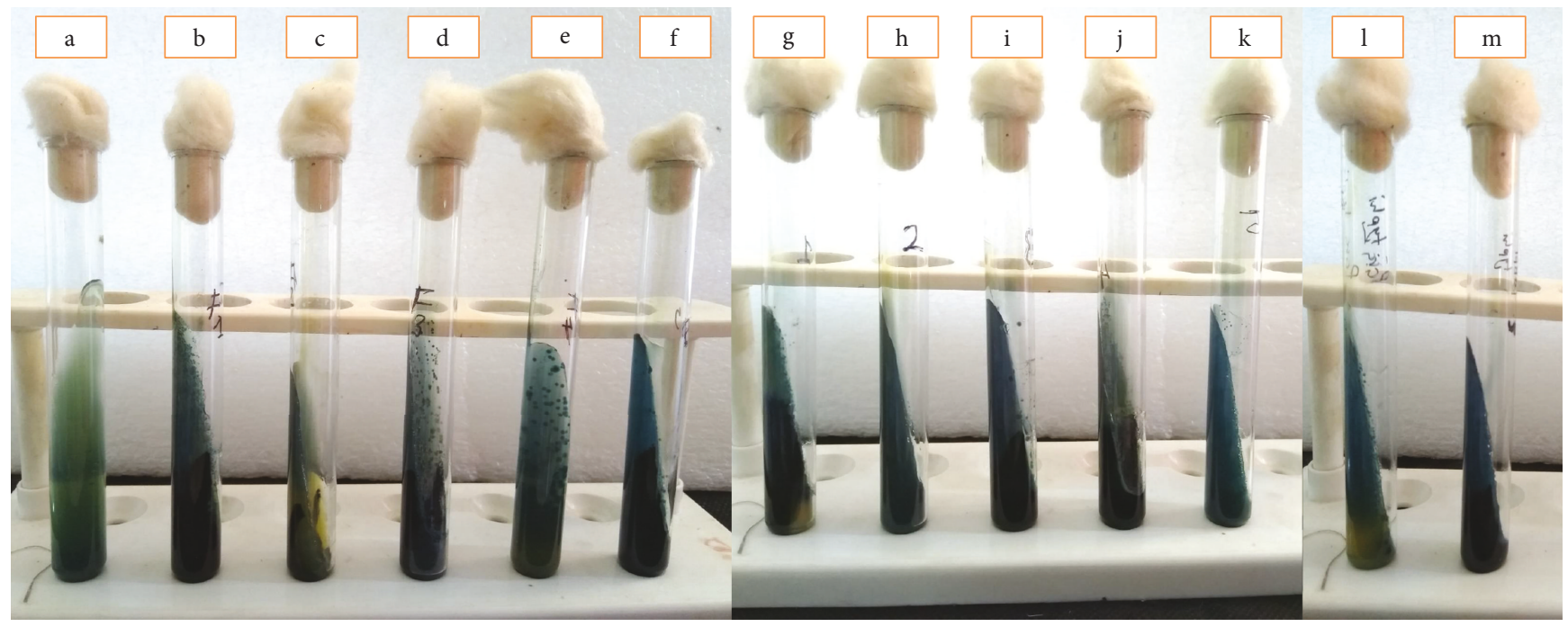

Figure 2: Thiosulfate-Citrate-Bile Salts-Sucrose (TCBS) after 24 hours of incubation. a: control; b-e: fish sample isolates; f: egg isolate; $\mathrm{g}-\mathrm{m}$ : clinical sample isolates.

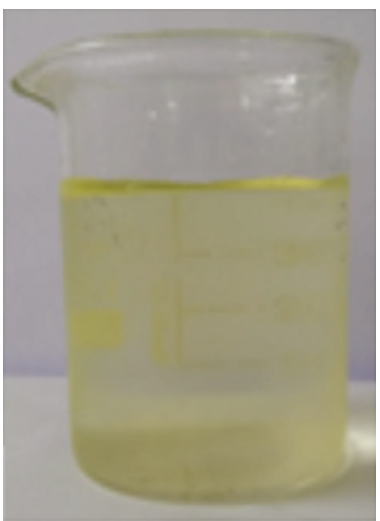

(a)

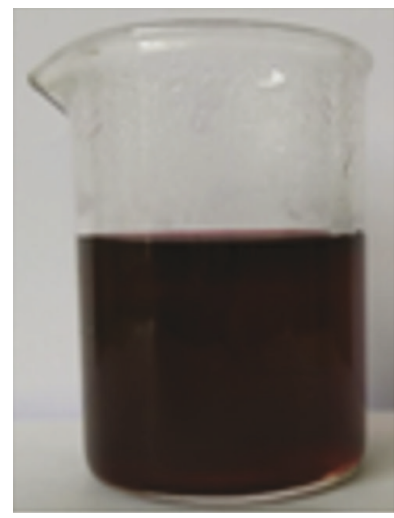

(b)

FIgURE 3: Synthesized gold nanoparticles (a) and gold ion solution (b).

3.4. UV-Vis Analysis. UV-visible absorption spectroscopy is the key to determine the structure and optical properties of metallic nanoparticles since the absorption bands are associated with the precise diameter and aspect ratio of metallic nanoparticles. The variation in the SPR was observed when analyzing the size effect of metallic nanoparticles. The 


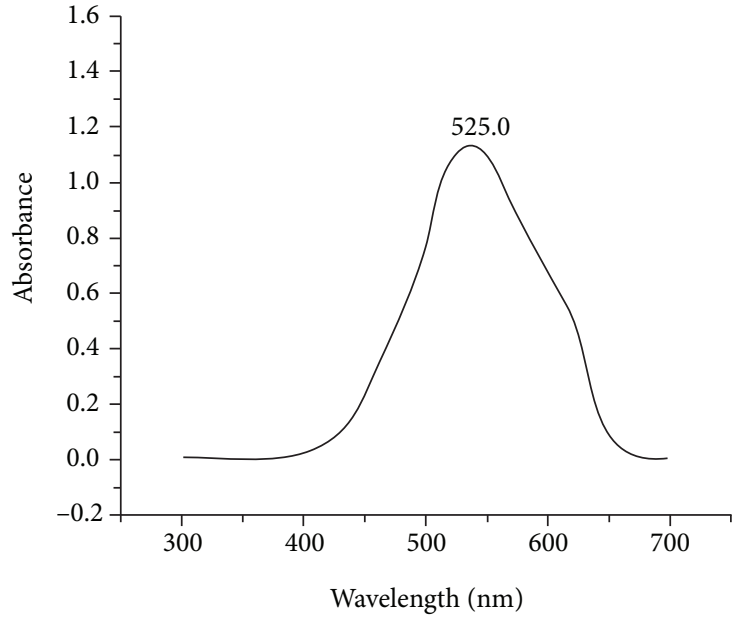

(a)

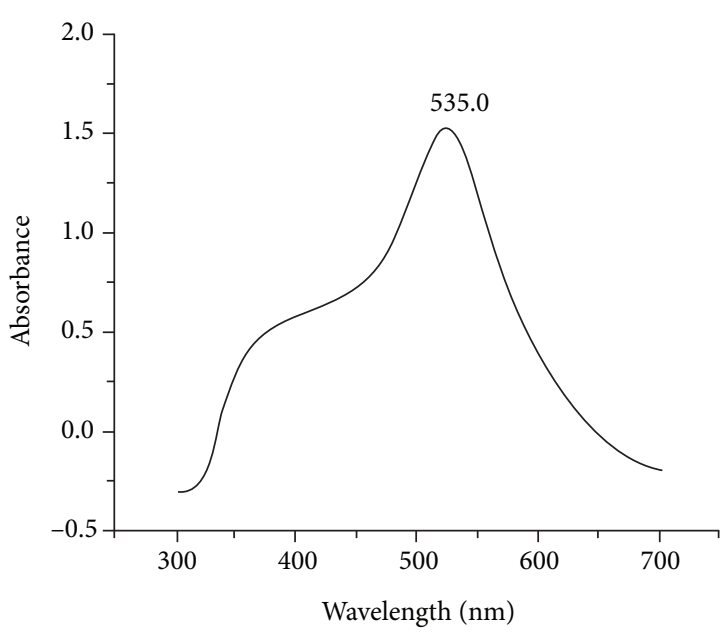

(b)

Figure 4: UV-visible peak of chemically synthesized GNPs. The graph in (a) depicts $525 \mathrm{~nm}$ (at zero hour) while that in (b) shows $535 \mathrm{~nm}$ (after 24 hours).

maximum surface plasmon (SP) absorption peak was found at $525 \mathrm{~nm}$ and $535 \mathrm{~nm}$ (Figure 4), which indicates the formation and presence of GNPs. The bright red color of the solution was due to the excitation of the surface of the SP vibration in GNPs. The surface plasmon resonance (SPR) peak of GNPs having a diameter of $\sim 30 \mathrm{~nm}$ correspond to the absorbance peak at a wavelength $\sim 525 \mathrm{~nm}$, as recorded in the literature $[12,48]$.

3.5. Fourier Transform Infrared Spectroscopy (FTIR) Analysis of GNPs. To record FTIR spectra, GNPs were analyzed using the instrument IRTracer-100 (Shimadzu, Japan). The FTIR spectra of the GNP powder in $\mathrm{KBr}$ pellets were used to identify GNP-associated molecules and to characterize the chemical surface of the synthesized GNPs [51].

Figure 5 shows the FTIR spectra of the chemically synthesized GNPs, scanned in the wavenumber range of $4000-750 \mathrm{~cm}^{-1}$ at a resolution of $1.0 \mathrm{~cm}^{-1}$. The spectral data recorded were analyzed on wavenumbers between the 3600 and $2500 \mathrm{~cm}^{-1}, 1760$ and $1690 \mathrm{~cm}^{-1}, 1440$ and $1395 \mathrm{~cm}^{-1}$, 1320 and $1210 \mathrm{~cm}^{-1}$, and 950 and $910 \mathrm{~cm}^{-1}$ regions, which correlate with the presence of hydroxyl groups, carboxyl groups, and carbonyl groups. The FTIR spectrum of the synthesized GNPs presents a large number of peaks between 3500 and $2500 \mathrm{~cm}^{-1}$ due to the $\mathrm{O}-\mathrm{H}$ stretching bands of alcohols and/or carboxylic acids. The $1760-1690 \mathrm{~cm}^{-1}$ spectral region shows the predominant absorption bands representing the ester, ketone, and carboxylic acid groups. From the FTIR of GNPs, the carbonyl bands were at around the $1732.08 \mathrm{~cm}^{-1}$ and $1620.21 \mathrm{~cm}^{-1}$ peaks which depicts the $\mathrm{C}=\mathrm{O}$ stretching bond. The $\mathrm{C}-\mathrm{O}$ stretching band was found at around $1222.87 \mathrm{~cm}^{-1}$ and $1087.85 \mathrm{~cm}^{-1}$. The absorption peaks attributed to the $\mathrm{O}-\mathrm{H}$ bending in plane shows around $1531.48 \mathrm{~cm}^{-1}$ and $1365.60 \mathrm{~cm}^{-1}$ while that of the $\mathrm{O}-\mathrm{H}$ bending out-of-plane is $806.25 \mathrm{~cm}^{-1}$.

These results were similar to those found in the literature $[52,53]$. The FTIR results obtained support the idea of conjugated ligands on the surface of GNPs and that enzymes reduce the gold chloride ions and cap the GNPs formed through the reduction process.

3.6. X-Ray Diffraction (XRD) Analysis. The crystallinity nature or crystal structure and phase change formation of the synthesized GNPs are demonstrated by XRD as shown in Figure 6. Samples are prepared by the drop casting of the gold solution on a glass surface. The diffracted peak shows very high crystalline and nanolevel particles with facecentered cubic crystallographic planes of GNPs. Their values at $2 \theta$ was observed to be at $38.4^{\circ}, 44.6^{\circ}, 64.6^{\circ}$, and $78.3^{\circ}$ for the indexing angles of reference planes (111), (200), (220), and (311), respectively (Figure 6). Similar results match those found in the literature as well $[12,54,66]$. This analysis clearly revealed the spherical structure of synthesized GNPs. Its intense narrow peaks also indicates the crystalline nature of the synthesized GNPs [66].

3.7. FESEM and TEM Analyses. The morphological features of GNPs were studied by a field emission scanning electron microscope (FESEM) using the GeminiSEM 500 by Carl Zeiss. The image as shown in Figure 7 indicates that the synthesized GNPs are round and spherical in shape having no nanoporous nature with agglomerations and has dimensions between 40 and $60 \mathrm{~nm}$ in the width of GNPs with a welldispersed property. The obtained result exhibited that almost all the particles are spherical and round in shape with agglomerations and a shape dimension of $1 \mu \mathrm{m}$ scale and $200 \mathrm{~nm}$ scale in $5.0 \mathrm{kV}$ in a width of $8.6 \mathrm{~mm}$ as observed, respectively, in $25.43 \mathrm{kX}$ and $111.31 \mathrm{kX}$ magnification, and the result was compared with the reports of [55] and was thus found to be similar to that found in the literature.

The TEM image as shown in Figure 8 indicate that the synthesized GNPs are spherical in shape with diameters ranging from 40 to $70 \mathrm{~nm}$.

Though the shape and morphology may affect the antibacterial activity, conclusive reports are lacking regarding 


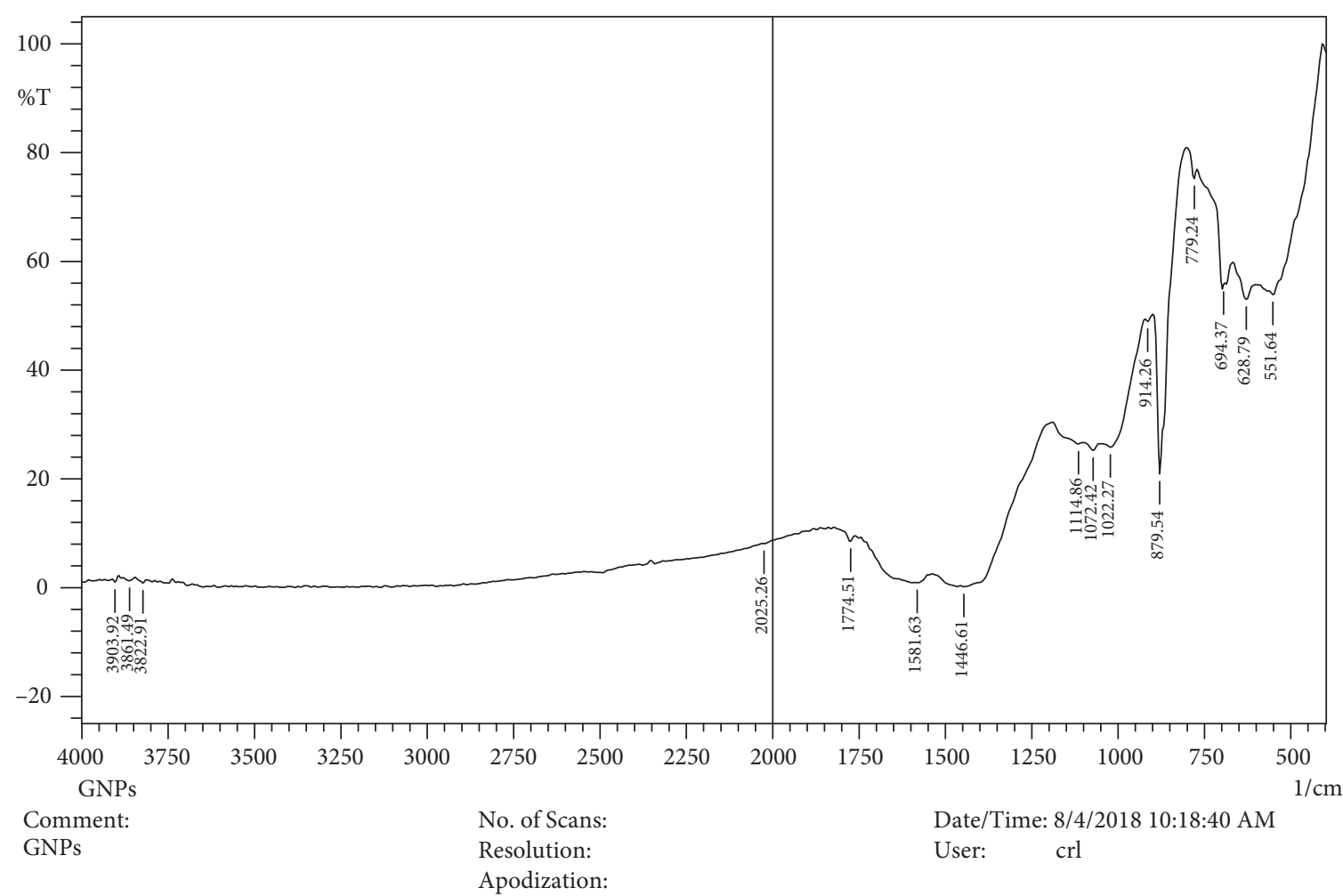

FIGURE 5: FTIR result of chemically synthesized GNPs.

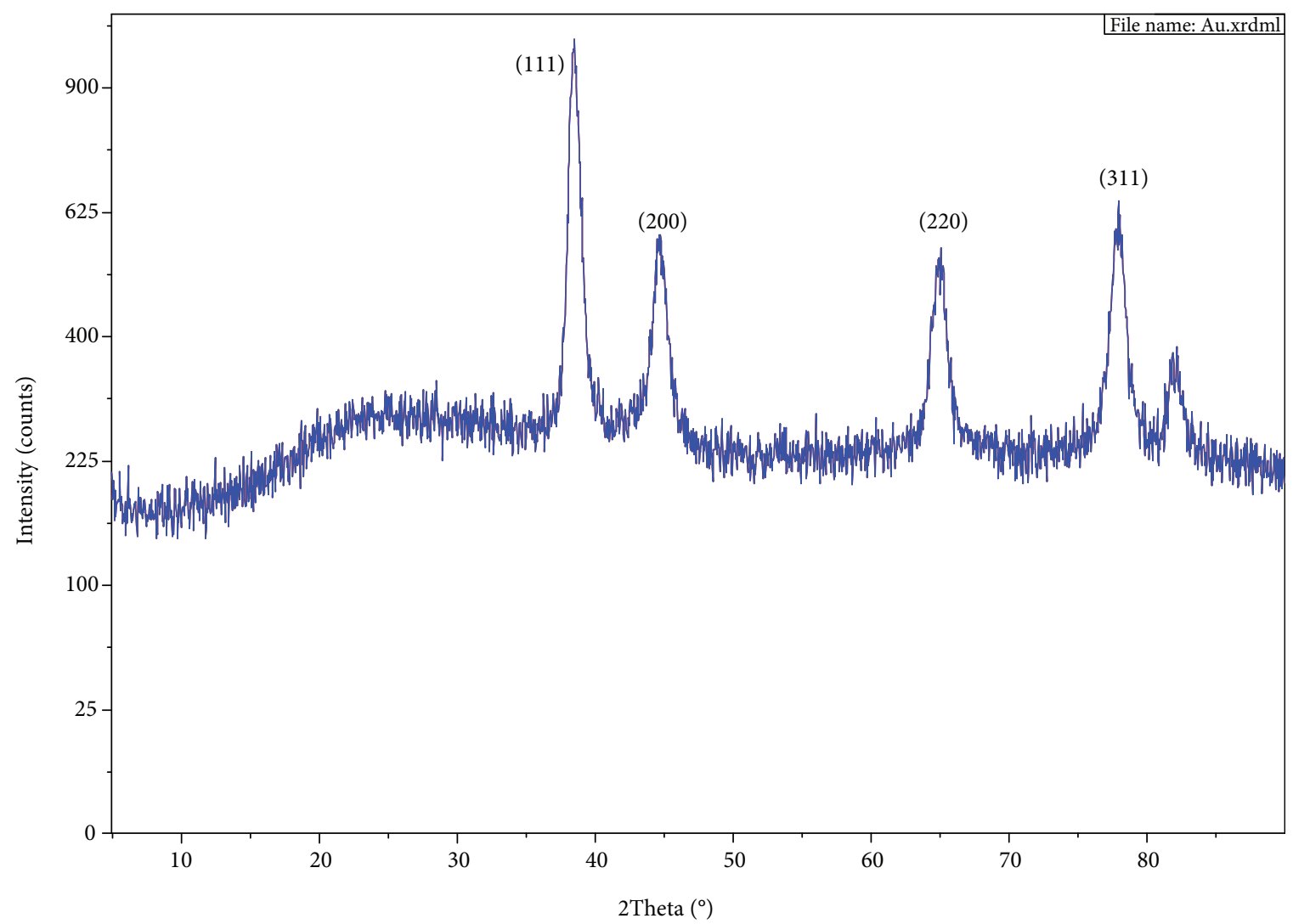

FiguRE 6: X-ray diffraction pattern of chemically synthesized GNPs. 


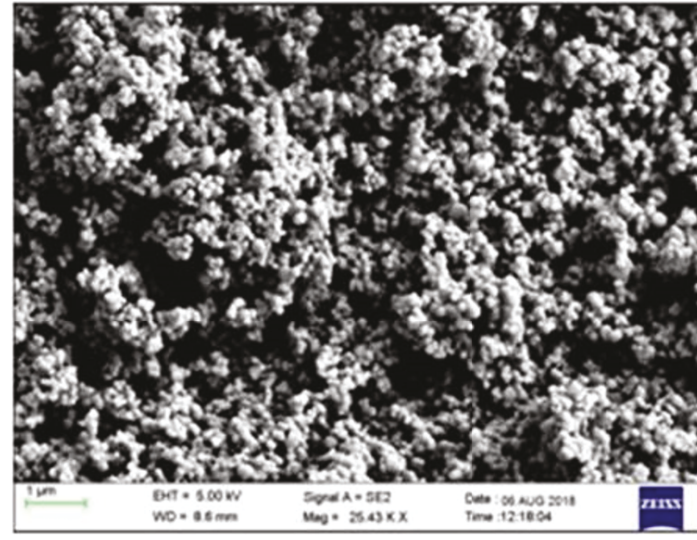

(a)

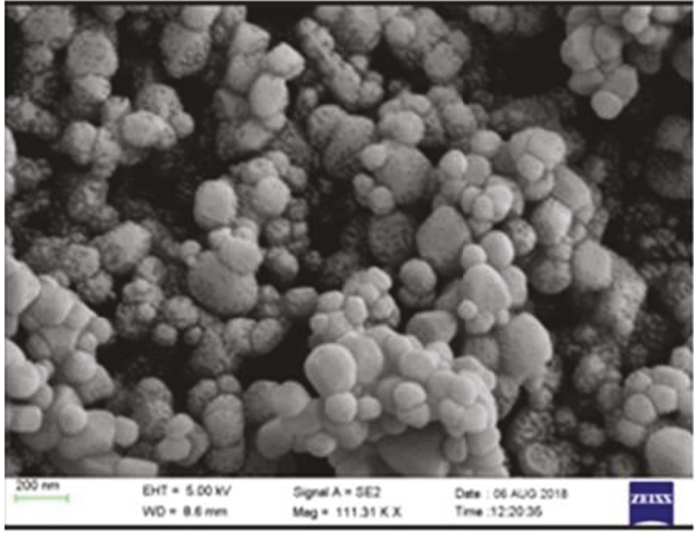

(b)

FIgURE 7: FESEM of the chemically synthesized GNPs. (a) Morphology at $1 \mu \mathrm{m}$ and (b) morphology at $200 \mathrm{~nm}$.

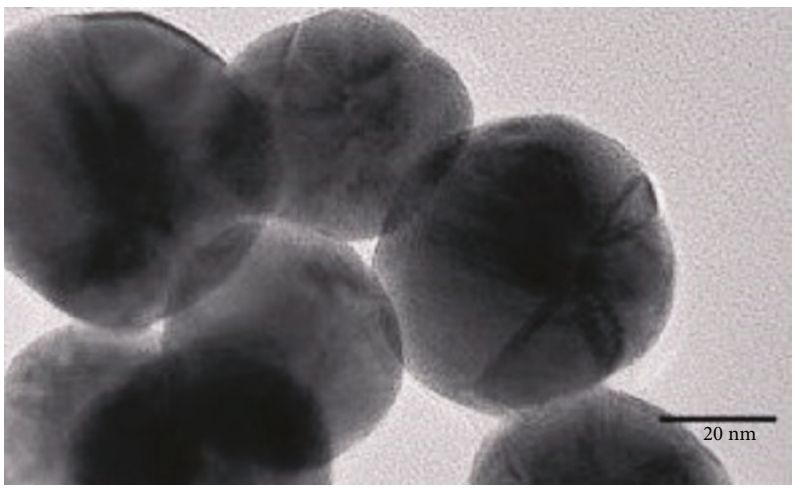

FIgURE 8: TEM of the chemically synthesized GNPs at a scale of $200 \mathrm{~nm}$.

the use of gold nanoplates and other nonspherical structures for the study of antibacterial inhibition of either grampositive or gram-negative bacteria. This may be because the diameter of the nanoplates has varied sizes which are usually characterized as larger particles (50-1000 nm) and irregular shapes and thickness, viz., hexagonal, obtuse triangular, or truncated triangular. Mostly, the particle sizes are not uniform and the synthesized smaller gold nanoplate is reported to be about 60-70 $\mathrm{nm}$ in size [56-62].

3.8. Dynamic Light Scattering (DLS) and Zeta Potential Analyses. The DLS and Zetasizer (Zetasizer Nano ZS90, Malvern Instruments Ltd., UK) analyses were carried out to determine the size distribution and also the surface charge of the chemically synthesized GNPs. This measurement helps to determine the electrophoretic mobility by measuring the size distribution and zeta potential and/or surface charge of the chemically synthesized GNPs. These instruments help in the analysis of dispersed particles and colloidal nanoparticles that yield to the particle size.

The zeta potential of the chemically synthesized GNPs was found at $-18.4 \mathrm{mV}$ (Figure 9(a)), which indicates its good stability. Nanoparticles are said to be highly stable if its zeta potential is more than $+30 \mathrm{mV}$ or less than $-30 \mathrm{mV}$
[63-65]. Also, the plot in Figure 9(b) shows the relative percentage of light scattering of the average particle size and the distinct peak was found at $91.28 \mathrm{~nm}$, which indicates the presence of nanoscale aggregates within the samples. This result was compared to that found in the literature and was found to be similar $[66,67]$.

3.9. Antimicrobial Mechanism and Antimicrobial Activity of GNPs and Gold Solution against Salmonella Isolates. Nanoparticles of gold exhibit some ability to attach themselves to the bacterial membrane by electrostatic interaction and disrupt its integrity $[68,69]$. GNPs can also cause leakage in cell wall contents and bind with DNA as they generate holes in the cell wall and inhibit transcription [70]. The GNPs aggregate within the bacterial biofilms and bind to their surface to induce cell wall distortions which are important in treatment durations and reduce the effect of it drugs [71]. The use of small nanometer GNPs interact with the bacteria, which likely induces a metabolic imbalance and results in an increase of intracellular oxidative stress production that culminates in the death of the bacteria [72]. Figure 10 shows the minimum inhibitory concentration (MIC) growth of the culture under study. The GNPs as well as the gold solution have very strong antimicrobial activities. The MIC 


\begin{tabular}{llll} 
Results & \multicolumn{1}{c}{ Mean (mV) } & Area (\%) & St Dev (mV) \\
& Peak 1: -18.4 & 100.0 & 4.40 \\
Zeta potential (mV): -18.4 & Peak 2: 0.00 & 0.0 & 0.00 \\
Zeta deviation (mV): 4.40 & Peak 3: 0.00 & 0.0 & 0.00 \\
Conductivity (mS/cm): 1.09 & & &
\end{tabular}

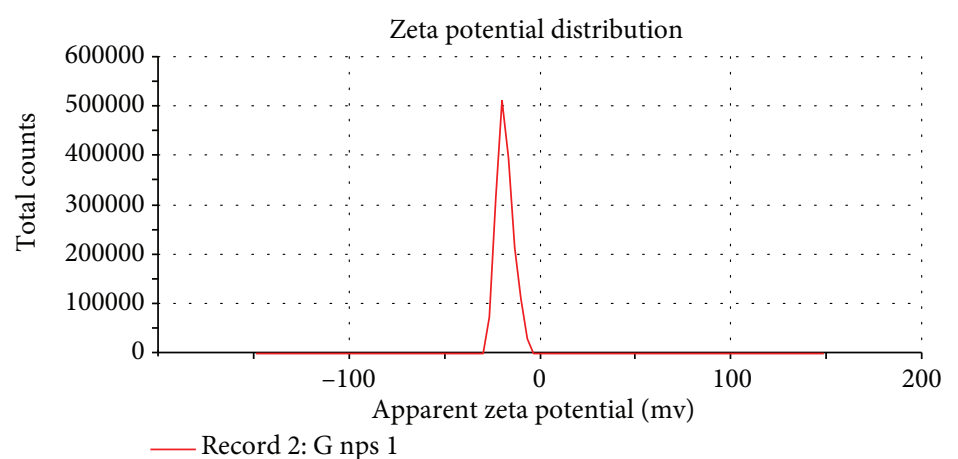

(a)

$\begin{array}{rlll} & & & \\ \text { Size (d.nm): } & \% \text { intensity: St Dev (d.nm) } \\ \text { Z-average (d.nm): } 4172 & \text { Peak 1: } 91.28 & 100.0 & 0.000 \\ \text { PdI: } 1.000 & \text { Peak 2: } 0.000 & 0.0 & 0.000 \\ \text { Intercept: } 1.38 & \text { Peak 3: } 0.000 & 0.0 & 0.000\end{array}$

Result quality: Refer to quality report

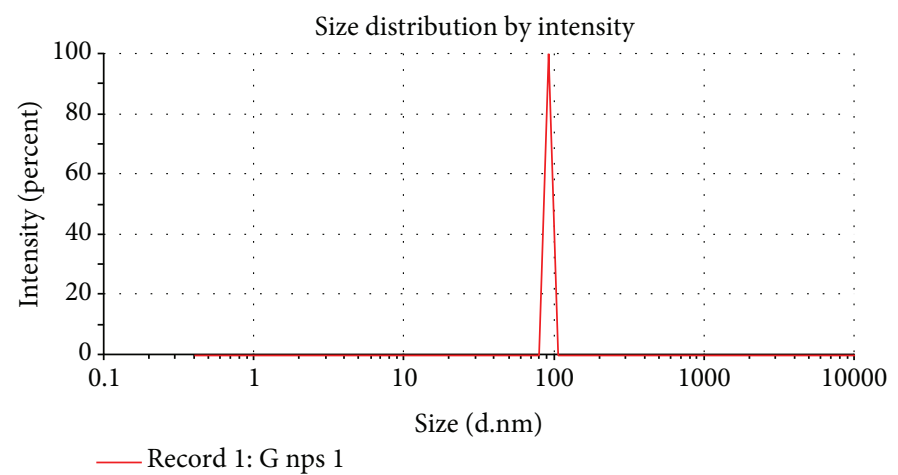

(b)

FIgure 9: (a) Zeta potential of the synthesized GNPs. (b) Particle size distribution of the synthesized GNPs.

values obtained demonstrated that the gold solution and GNPs were inhibited at different values against human pathogenic gram-negative bacteria like Salmonella.

The maximum antibacterial activity of the synthesized GNPs in doses of $25 \mu \mathrm{L} / \mathrm{mL}$ and $50 \mu \mathrm{L} / \mathrm{mL}$ of GNPs and 10 $\mu \mathrm{L} / \mathrm{mL}$ of gold solution were recorded at $11 \mathrm{~mm}, 10 \mathrm{~mm}$, and $9 \mathrm{~mm}$, respectively, of the collected samples under study; in the literature, a similar result was found $[12,66]$. This confirms that higher doses of GNPs can exhibit a good antibacterial potential against the Salmonella strains which is gram negative when compared to gram-positive strains as confirmed $[12,50,66]$ in the literature. The size of GNPs significantly affects the antimicrobial activity. Literature reveals that GNPs as small as $10-25 \mathrm{~nm}$ contribute to highperformance antimicrobial activity with nearly $44 \%$ inhibition, while that of the $35-60 \mathrm{~nm}$ particle size resulted in less antimicrobial activity with $22 \%$ inhibition $[12,73,74]$.
The smaller particle size accounts for their high surface area to volume ratio and surface charge which significantly influence their cellular uptake through enhanced interaction with biomolecules within the cell and on the cell surface $[2,74]$.

\section{Conclusion}

In conclusion, human pathogenic gram-negative bacterial strains of Salmonella were isolated successfully and were biochemically confirmed. The MIC values obtained also demonstrated a good potential stability of GNPs for inhibition against Salmonella spp. The synthesized GNPs were confirmed by UV-visible spectroscopy, XRD, FTIR, FESEM, TEM, DLS, and zeta potential. The particle size of the synthesized GNPs was estimated to be in the range from $30 \mathrm{~nm}$ to $40 \mathrm{~nm}$ as per the UV-Vis plasmon value which stabilized at 


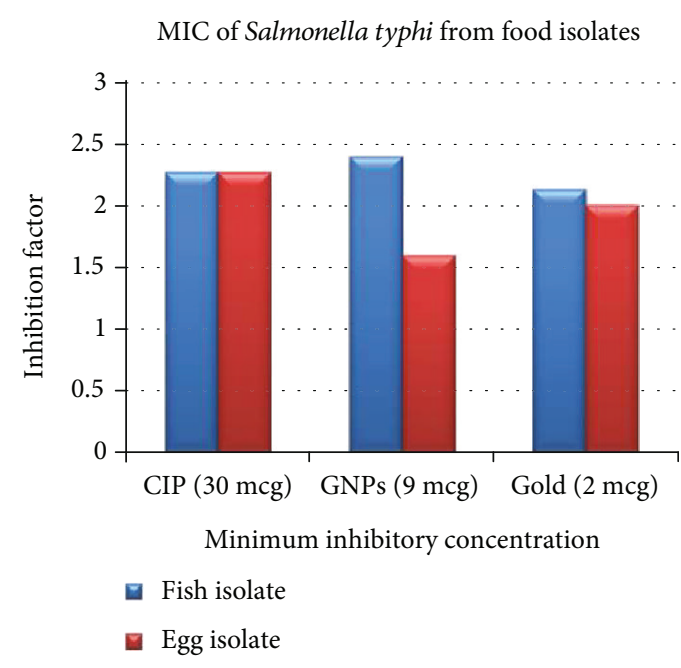

(a)

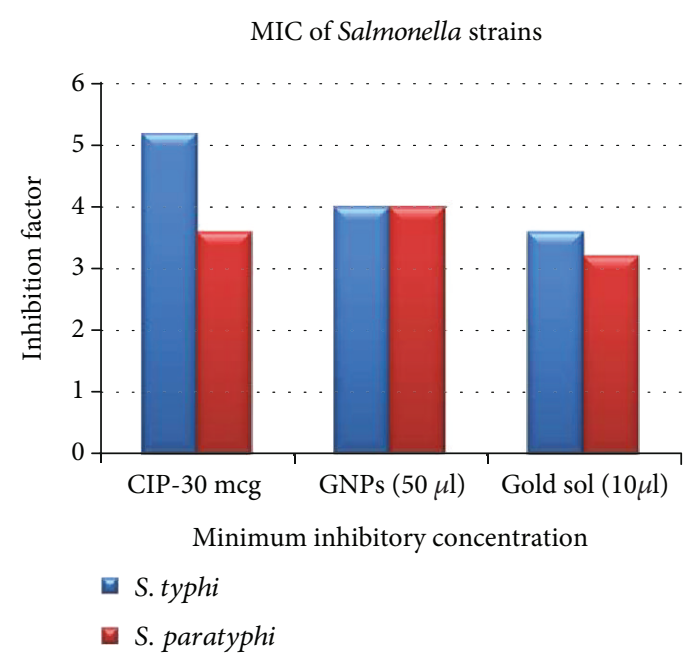

(b)

FIgURE 10: Minimum inhibition concentration (MIC) of Salmonella from food isolates (a) and clinical isolates (b) after 24 hours of incubation.

$90 \mathrm{~nm}$ after 24 hours. The synthesized GNPs are spherical and round in shape as confirmed by the use of FESEM. The zeta potential surface charge was stable at $-18.4 \mathrm{mV}$. The $\mathrm{pH}$, incubation condition, and the temperature conditions did not affect the growth of the GNPs. Finally, the GNPs show active and stable antibacterial activity for gramnegative Salmonella strains. Due to this significant antimicrobial efficacy, it has potential applications in the field of biomedicine as an alternative to antibiotics and further formulation for detection and treatment of typhoid.

\section{Data Availability}

The data used to support the findings of this study are included within the article.

\section{Conflicts of Interest}

The authors declare that there is no conflict of interest with regard to the publication of this paper.

\section{Authors' Contributions}

The laboratory work and compilation of script was achieved by Mercy Adusei Boatemaa under the full supervision of R. Ragunathan and the guidance of J. Naskar.

\section{Acknowledgments}

The authors are sincerely thankful to SHUATS and CBNR for providing all the facilities required for the study. This work was supported by All Nations University College, Koforidua, Ghana and Sam Higginbottom University of Agriculture, Technology, and Sciences, Allahabad, U.P., India.

\section{References}

[1] Y. Zhou, Y. Kong, S. Kundu, J. D. Cirillo, and H. Liang, “Antibacterial activities of gold and silver nanoparticles against
Escherichia coli and bacillus Calmette-Guérin," Journal of Nanobiotechnology, vol. 10, no. 1, p. 19, 2012.

[2] B. Aderibigbe, "Metal-based nanoparticles for the treatment of infectious diseases," Molecules, vol. 22, no. 8, p. 1370, 2017.

[3] E. Morales-Avila, G. Ferro-Flores, B. E. Ocampo-García et al., "Antibacterial efficacy of gold and silver nanoparticles functionalized with the ubiquicidin (29-41) antimicrobial peptide," Journal of Nanomaterials, vol. 2017, 10 pages, 2017.

[4] S. M. Irayyif, A. M. S. Araghiand, and S. Malla, "Silver nanoparticles and their effect on the biofilm formation in food borne Salmonella species," International Journal of Recent Scientific Research, vol. 6, pp. 4343-4346, 2015.

[5] S. Antariksh, R. M. Tripathi, and R. P. Singh, "Biological synthesis of silver nanoparticles by using onion (Allium cepa) extract and their antibacterial activity," Digest Journal of Nanomaterials and Biostructures, vol. 5, pp. 427-432, 2010.

[6] H. Deng, D. McShan, Y. Zhang et al., "Mechanistic study of the synergistic antibacterial activity of combined silver nanoparticles and common antibiotics," Environmental Science \& Technology, vol. 50, no. 16, pp. 8840-8848, 2016.

[7] P. Prema and S. Thangapandiyan, "In-vitro antibacterial activity of gold nanoparticles capped with polysaccharide stabilizing agents," International Journal of Pharmacy and Pharmaceutical Sciences, vol. 5, pp. 310-314, 2013.

[8] D. MubarakAli, N. Thajuddin, K. Jeganathan, and M. Gunasekaran, "Plant extract mediated synthesis of silver and gold nanoparticles and its antibacterial activity against clinically isolated pathogens," Colloids and Surfaces B: Biointerfaces, vol. 85, no. 2, pp. 360-365, 2011.

[9] K. Umamaheswari, R. Baskar, K. Chandru, N. Rajendiran, and S. Chandirasekar, "Antibacterial activity of gold nanoparticles and their toxicity assessment," BMC Infectious Diseases, vol. 14, Supplement 3, p. 64, 2014.

[10] G. Bond, "The early history of catalysis by gold," Gold Bull, vol. 41, no. 3, pp. 235-241, 2008.

[11] R. Meyer, C. Lemire, S. K. Shaikhutdinov, and H. . J. Freund, "Surface chemistry of catalysis by gold," Gold Bull, vol. 37, no. 1-2, pp. 72-124, 2004. 
[12] S. Shamaila, N. Zafar, S. Riaz, R. Sharif, J. Nazir, and S. Naseem, "Gold nanoparticles: an efficient antimicrobial agent against enteric bacterial human pathogen," Nanomaterials, vol. 6, no. 4, p. 71, 2016.

[13] M. G. Blaber, M. D. Arnold, N. Harris, M. J. Ford, and M. B. Cortie, "Plasmon absorption in nanospheres: A comparison of sodium, potassium, aluminium, silver and gold," Physica B: Condensed Matter, vol. 394, no. 2, pp. 184-187, 2007.

[14] S. Sun, P. Mendes, K. Critchley et al., "Fabrication of gold micro- and nanostructures by photolithographic exposure of thiol-stabilized gold nanoparticles," Nano Letters, vol. 6, no. 3, pp. 345-350, 2006.

[15] T. Bakhishev and V. Subramanian, "Investigation of gold nanoparticle inks for low-temperature lead-free packaging technology," Journal of Electronic Materials, vol. 38, no. 12, pp. 2720-2725, 2009.

[16] K. L. Kelly, E. Coronado, L. L. Zhao, and G. C. Schatz, "The optical properties of metal nanoparticles: the influence of size, shape, and dielectric environment," The Journal of Physical Chemistry B, vol. 107, no. 3, pp. 668-677, 2003.

[17] M. C. Daniel and D. Astruc, "Gold nanoparticles: assembly, supramolecular chemistry, quantum-size-related properties, and applications toward biology, catalysis, and nanotechnology," Chemical Reviews, vol. 104, no. 1, pp. 293-346, 2004.

[18] N. T. Thanh and Z. Rosenzweig, "Development of an aggregation-based immunoassay for anti-protein A using gold nanoparticles," Analytical Chemistry, vol. 74, no. 7, pp. 16241628, 2002.

[19] Z. Fan, P. P. Fu, H. Yu, and P. C. Ray, "Theranostic nanomedicine for cancer detection and treatment," Journal of Food and Drug Analysis, vol. 22, no. 1, pp. 3-17, 2014.

[20] K. P. Lisha, Anshup, and T. Pradeep, "Towards a practical solution for removing inorganic mercury from drinking water using gold nanoparticles," Gold Bull, vol. 42, no. 2, pp. 144$152,2009$.

[21] M. Brust, M. Walker, D. Bethell, D. J. Schiffrin, and R. Whyman, "Synthesis of thiol-derivatised gold nanoparticles in a two-phase liquid-liquid system," Journal of the Chemical Society, Chemical Communications, vol. 0, no. 7, pp. 801-802, 1994.

[22] B. K. Pong, H. I. Elim, J. X. Chong, W. Ji, B. L. Trout, and J. Y. Lee, "New insights on the nanoparticle growth mechanism in the citrate reduction of gold (III) salt: formation of the $\mathrm{Au}$ nanowire intermediate and its nonlinear optical properties," The Journal of Physical Chemistry C, vol. 111, no. 17, pp. 6281-6287, 2007.

[23] N. L. Rosi and C. A. Mirkin, "Nanostructures in biodiagnostics," Chemical Reviews, vol. 105, no. 4, pp. 1547-1562, 2005.

[24] S. R. Hall, W. Shenton, H. Engelhardt, and S. Mann, "Sitespecific organization of gold nanoparticles by biomolecular templating," ChemPhysChem, vol. 2, no. 3, pp. 184-186, 2001.

[25] D. Pissuwan, C. H. Cortie, S. M. Valenzuela, and M. B. Cortie, "Functionalised gold nanoparticles for controlling pathogenic bacteria," Trends in Biotechnology, vol. 28, no. 4, pp. 207213, 2010.

[26] V. Pokharkar, D. Bhumkar, K. Suresh, Y. Shinde, S. Gairola, and S. S. Jadhav, "Gold nanoparticles as a potential carrier for transmucosal vaccine delivery," Journal of Biomedical Nanotechnology, vol. 7, no. 1, pp. 57-59, 2011.

[27] S. Eustis and M. A. El-Sayed, "Why gold nanoparticles are more precious than pretty gold: noble metal surface plasmon resonance and its enhancement of the radiative and nonradiative properties of nanocrystals of different shapes," Chemical Society Reviews, vol. 35, no. 3, pp. 209-217, 2006.

[28] J. Kimling, M. Maier, B. Okenve, V. Kotaidis, H. Ballot, and A. Plech, "Turkevich method for gold nanoparticle synthesis revisited," The Journal of Physical Chemistry B, vol. 110, no. 32, pp. 15700-15707, 2006.

[29] S. Mandal, "Synthesis of radioactive gold nanoparticle in surfactant medium," Journal of Radioanalytical and Nuclear Chemistry, vol. 299, no. 3, pp. 1209-1212, 2014.

[30] F. Porta and M. Rossi, "Gold nanostructured materials for the selective liquid phase catalytic oxidation," Journal of Molecular Catalysis A: Chemical, vol. 204-205, pp. 553-559, 2003.

[31] R. Shenhar, T. B. Norsten, and V. M. Rotello, "Polymermediated nanoparticle assembly structural control and applications," Advanced Materials, vol. 17, no. 6, pp. 657-669, 2005.

[32] Y. Zhou, C. Y. Wang, Y. R. Zhu, and Z. Y. Chen, "A Novel Ultraviolet Irradiation Technique for Shape-Controlled Synthesis of Gold Nanoparticles at Room Temperature," Chemistry of Materials, vol. 11, no. 9, pp. 2310-2312, 1999.

[33] T. K. Sau, A. Pal, N. R. Jana, Z. L. Wang, and T. Pal, "Size controlled synthesis of gold nanoparticle using photochemically prepared seed," Journal of Nanoparticle Research, vol. 3, no. 4, pp. 257-261, 2001.

[34] K. Okitsu, M. Ashokkumar, and F. Grieser, "Sonochemical synthesis of gold nanoparticles: effects of ultrasound frequency," The Journal of Physical Chemistry B, vol. 109, no. 44, pp. 20673-20675, 2005.

[35] L. P. Jiang, S. Xu, J. M. Zhu, J. R. Zhang, J. J. Zhu, and H. Y. Chen, "Ultrasonic-Assisted Synthesis of Monodisperse Single-Crystalline Silver Nanoplates and Gold Nanorings," Inorganic Chemistry, vol. 43, no. 19, pp. 5877-5883, 2004.

[36] P. Matteini, F. Ratto, F. Rossi, S. Centi, L. Dei, and R. Pini, "Chitosan films doped with gold nanorod as laser-activatable hybried bioadhesives," Advanced Materials, vol. 22, no. 38, pp. 4313-4316, 2010.

[37] M. Sengani, A. M. Grumezescu, and V. D. Rajeswari, "Recent trends and methodologies in gold nanoparticle synthesis-a prospective review on drug delivery aspect," OpenNano, vol. 2, pp. 37-46, 2017.

[38] J. Polte, T. T. Ahner, F. Delissen et al., "Mechanism of gold nanoparticle formation in the classical citrate synthesis method derived from coupled in situ XANES and SAXS evaluation," Journal of the American Chemical Society, vol. 132, no. 4, pp. 1296-1301, 2010.

[39] M. Grzelczak, J. Pérez-Juste, P. Mulvaney, and L. M. LizMarzán, "Shape control in gold nanoparticle synthesis," Chemical Society Reviews, vol. 37, no. 9, pp. 1783-1791, 2008.

[40] P. Zhao, N. Li, and D. Astruc, "State of the art in gold nanoparticle synthesis," Coordination Chemistry Reviews, vol. 257, no. 3-4, pp. 638-665, 2013.

[41] R. Herizchi, E. Abbasi, M. Milani, and A. Akbarzadeh, "Current methods for synthesis of gold nanoparticles," Artificial Cells, Nanomedicine, and Biotechnology, vol. 44, no. 2, pp. 596-602, 2014.

[42] C. Li, D. Li, G. Wan, J. Xu, and W. Hou, "Facile synthesis of concentrated gold nanoparticles with low size-distribution in water: temperature and $\mathrm{pH}$ controls," Nanoscale Research Letters, vol. 6, no. 1, pp. 1-10, 2011.

[43] M. K. Nesa, M. S. R. Khan, and M. Alam, "Isolation, identification and characterization of Salmonella serovars from 
diarrhoeic stool samples of human," Bangladesh Journal of Veterinary Medicine, vol. 9, no. 1, pp. 85-93, 2011.

[44] A. A. AL-Iedani, M. H. Khudor, and N. M. Oufi, "Isolation and identification of Salmonella spp. from poultry farms by using different techniques and evaluation of their antimicrobial susceptibilities," Basrah Journal of Veterinary Research, vol. 1, p. 1, 2014.

[45] W. Douglas, R. Waltman, K. Gast, and E. T. Mallinson, Salmonellosis. A Laboratory Manual for the Isolation and Identification of Avian Pathogens, American Association of Avian Pathologists, Kenett Square, 4th edn edition, 1998.

[46] OIE, Manual of Standards for Diagnostic Tests and Vaccines, Office International Des Epizooties, 2000.

[47] A. W. Bauer, W. M. M. Kirby, J. C. Sherris, and M. Turck, "Antibiotic susceptibility testing by a standardized single disc method," American Journal of Clinical Pathology, vol. 45, no. 4_ts, pp. 493-496, 1966.

[48] J. C. Martínez, N. A. Chequer, T. Cordova, and J. L. González, "Alternative methodology for gold nanoparticles diameter characterization using PCA technique and UV-Vis spectrophotometry," Nanoscience and Nanotechnology, vol. 2, no. 6, pp. 184-189, 2012.

[49] S. Cui, J. Zheng, and J. Meng, "An improved method for rapid isolation of salmonella against proteus in chicken carcasses," Journal of Food Safety, vol. 26, no. 1, pp. 49-61, 2006.

[50] T. Gunasegaran, X. Rathinam, M. Kasi, K. Sathasivam, S. Sreenivasan, and S. Subramaniam, "Isolation and identification of Salmonella from curry samples and its sensitivity to commercial antibiotics and aqueous extracts of Camelia sinensis (L.) and Trachyspermum ammi (L.)," Asian Pacific Journal of Tropical Biomedicine, vol. 1, no. 4, pp. 266-269, 2011.

[51] R. M. Amir, F. M. Anjum, M. I. Khan, M. R. Khan, I. Pasha, and M. Nadeem, "Application of Fourier transform infrared (FTIR) spectroscopy for the identification of wheat varieties," Journal of Food Science and Technology, vol. 50, no. 5, pp. 1018-1023, 2013.

[52] D. N. Correa-Llantén, S. A. Muñoz-Ibacache, M. E. Castro, P. A. Muñoz, and J. M. Blamey, "Gold nanoparticles synthesized by Geobacillus sp. strain ID17 a thermophilic bacterium isolated from Deception Island, Antarctica," Microbial Cell Factories, vol. 12, no. 1, p. 75, 2013.

[53] G. L. Radu, G. I. Truică, R. Penu, V. Moroeanu, and S. C. Litescu, "Use of the Fourier transform infrared spectroscopy in characterization of specific samples," UPB Scientific Bulletin, Series B, vol. 74, no. 4, 2012.

[54] A. K. Suresh, D. A. Pelletier, W. Wang et al., "Biofabrication of discrete spherical gold nanoparticles using the metal reducing bacterium Shewanella oneidensis," Acta Biomaterialia, vol. 7, pp. 2148-2152, 2012.

[55] I. Khan, K. Saeed, and I. Khan, "Nanoparticles: properties, applications and toxicities," Arabian Journal of Chemistry, 2017.

[56] H. J. Chen and D. Wen, "Ultrasonic-aided fabrication of gold nanofluids," Nanoscale Research Letters, vol. 6, no. 1, 2011.

[57] S. Yang, T. Zhang, L. Zhang, S. Wang, Z. Yang, and B. Ding, "Continuous synthesis of gold nanoparticles and nanoplates with controlled size and shape under UV irradiation," Colloids and Surfaces A: Physicochemical and Engineering Aspects, vol. 296, no. 1-3, pp. 37-44, 2007.

[58] Z. Yang, Z. Li, X. Lu et al., "Controllable biosynthesis and properties of gold nanoplates using yeast extract," Nano-Micro Letters, vol. 9, no. 1, p. 5, 2017.
[59] L. Wang, X. Wu, X. Li, L. Wang, M. Pei, and X. Tao, "Facile synthesis of concave gold nanoplates in hexagonal liquid crystal made of SDS/water system," Chemical Communications, vol. 46, no. 44, pp. 8422-8423, 2010.

[60] Y. Liu, L. Yang, and Y. Shen, "Hydrothermal synthesis of gold nanoplates and their structure dependent LSPR properties," Journal of Materials Research, vol. 33, no. 18, pp. 2671-2679, 2018.

[61] S. Hong, K. L. Shuford, and S. Park, "Shape transformation of gold nanoplates and their surface plasmon characterization: triangular to hexagonal nanoplates," Chemistry of Materials, vol. 23, no. 8, pp. 2011-2013, 2011.

[62] G. Zhan, L. Ke, Q. Li et al., "Synthesis of gold nanoplates with bioreducing agent using syringe pumps: a kinetic control," Industrial and Engineering Chemistry Research, vol. 51, no. 48, pp. 15753-15762, 2012.

[63] H. Barabadi, S. Honary, P. Ebrahimi, M. A. Mohammadi, A. Alizadeh, and F. Naghibi, "Microbial mediated preparation, characterization and optimization of gold nanoparticles," Brazilian Journal of Microbiology, vol. 45, no. 4, pp. 1493-1501, 2014.

[64] A. Tripathi, S. Kumari, and A. Kumar, "Toxicity evaluation of $\mathrm{pH}$ dependent stable Achyranthes aspera herbal gold nanoparticles," Applied Nanoscience, vol. 6, no. 1, pp. 61-69, 2016.

[65] A. Husen, "Gold nanoparticles from plant system: synthesis, characterization and their application," Nanoscience and Plant-Soil Systems, vol. 48, 2017.

[66] S. Kundu, "Gold nanoparticles: their application as antimicrobial agents and vehicles of gene delivery," Advances in Biotechnology \& Microbiology, vol. 4, no. 5, pp. 555-658, 2017.

[67] P. K. Tiwari and S. Y. Lee, "Gene delivery in conjunction with gold nanoparticle and tumor treating electric field," Journal of Applied Physics, vol. 114, no. 5, p. 5, 2013.

[68] A. Rai, A. Prabhune, and C. C. Perry, "Antibiotic mediated synthesis of gold nanoparticles with potent antimicrobial activity and their application in antimicrobial coatings," Journal of Materials Chemistry, vol. 20, no. 32, pp. 6789-6798, 2010.

[69] M. F. Zawrah and S. A. El-Moez, "Antimicrobial activities of gold nanoparticles against major foodborne pathogens," Life Science Journal, vol. 8, no. 4, pp. 37-44, 2011.

[70] K. Zheng, M. I. Setyawati, D. T. Leong, and J. Xie, "Antimicrobial gold nanoclusters,” ACS Nano, vol. 11, no. 7, pp. 69046910, 2017.

[71] S. Senthilkumar, L. Kashinath, M. Ashok, and A. Rajendran, "Antibacterial properties and mechanism of gold nanoparticles obtained from Pergularia daemia leaf extract," Journal of Nanomedicine Research, vol. 6, no. 1, p. 146, 2017.

[72] Q. Yu, J. Li, Y. Zhang, Y. Wang, L. Liu, and M. Li, "Inhibition of gold nanoparticles (AuNPs) on pathogenic biofilm formation and invasion to host cells," Scientific Reports, vol. 6, no. $1,2016$.

[73] C. Lin, K. Tao, D. Hua, Z. Ma, and S. Zhou, "Size effect of gold nanoparticles in catalytic reduction of p-nitrophenol with $\mathrm{NaBH}_{4}$," Molecules, vol. 18, no. 10, pp. 12609-12620, 2013.

[74] M. Raza, Z. Kanwal, A. Rauf, A. Sabri, S. Riaz, and S. Naseem, "Size- and shape-dependent antibacterial studies of silver nanoparticles synthesized by wet chemical routes," Nanomaterials, vol. 6, no. 4, p. 74, 2016. 


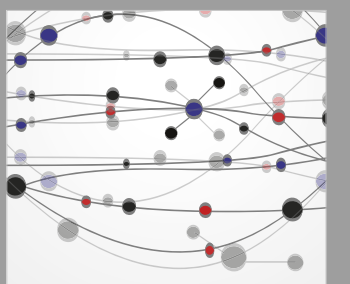

The Scientific World Journal
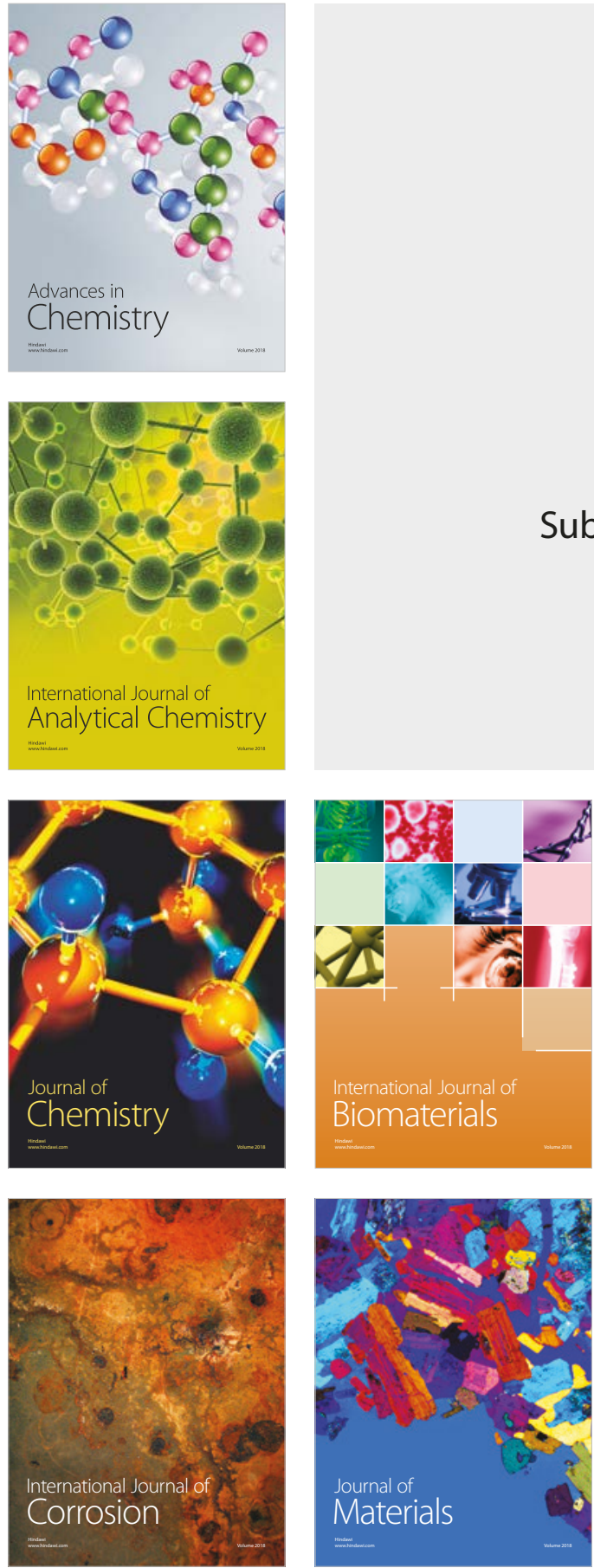

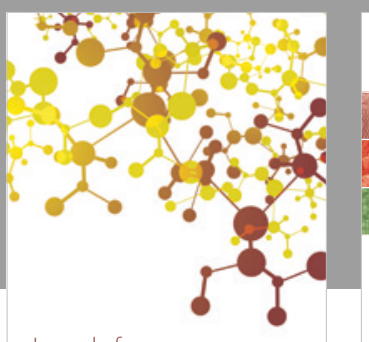

Journal of

Applied Chemistry
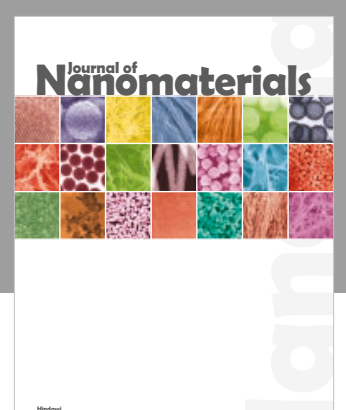

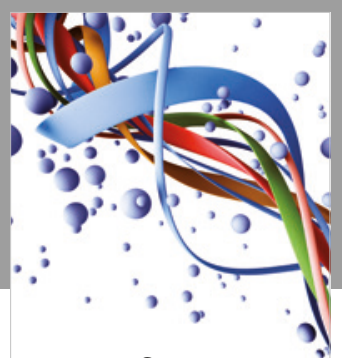

Scientifica

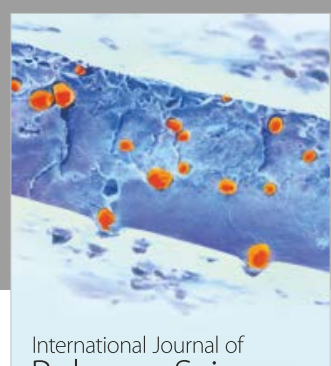

Polymer Science

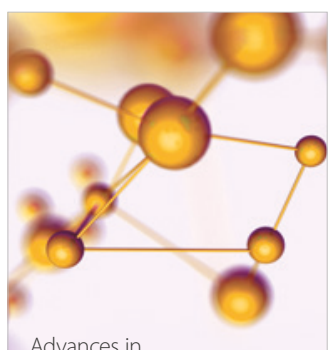

Physical Chemistry
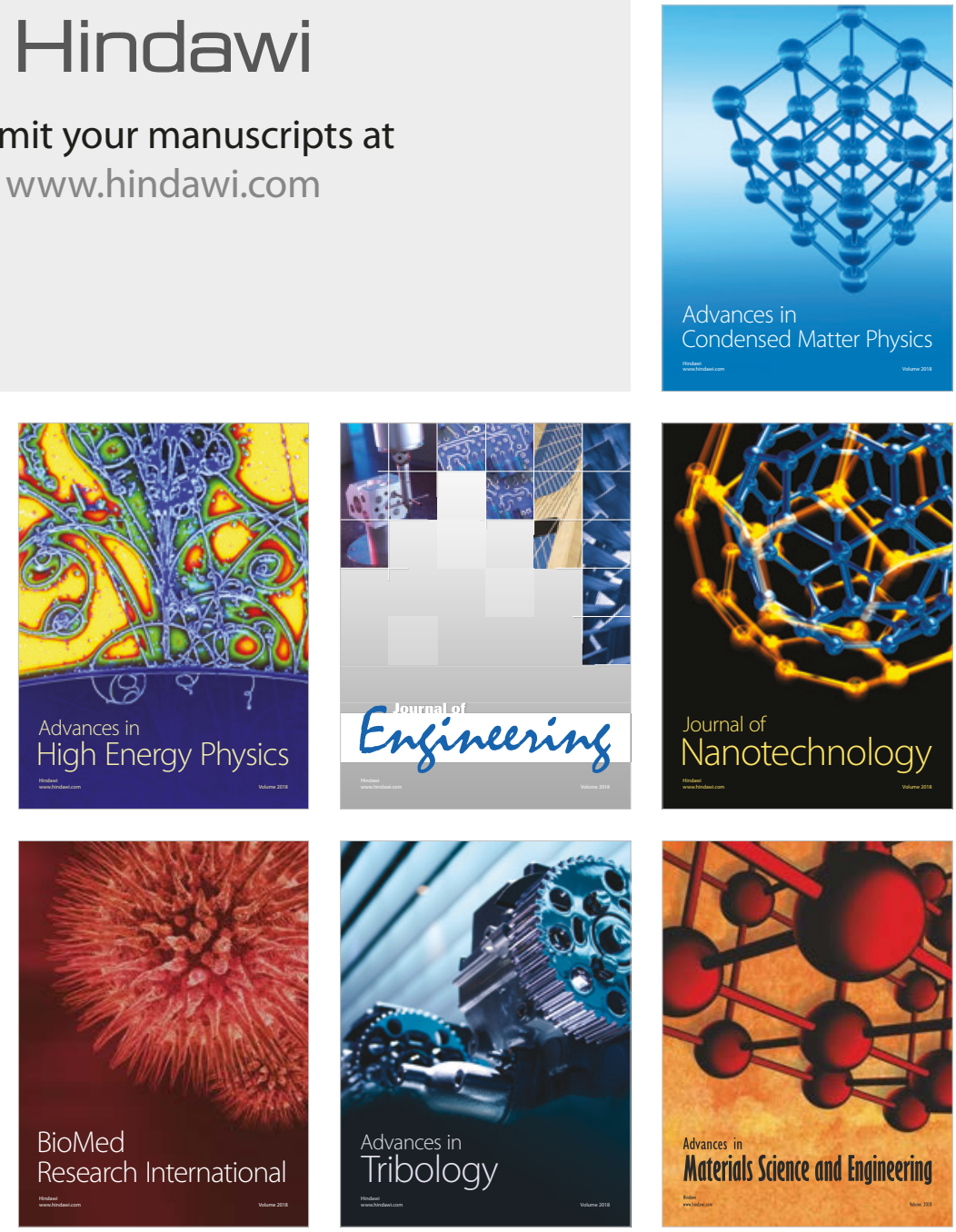